\title{
CIRCUITO DE AUTORREGULAÇÃO DA APRENDIZAGEM: INTERLOCUÇõES COM OS UNIVERSITÁRIOS
}

\author{
Lourdes Maria Bragagnolo Frison ${ }^{1}$ \\ Célia Artemisa Gomes Rodrigues Miranda²
}

Resumo: Este artigo tem por objetivo analisar os significados e os desafios enfrentados por estudantes universitários a partir de oficinas que investiram em práticas associadas à autorregulação da aprendizagem no contexto universitário. 0 trabalho faz parte do projeto de pesquisa "Modos de aprender no ambiente universitário: da autorregulação aos projetos de vida", que inclui o Circuito APRENDIZagem: autorregulação para aprender, realizado pelo grupo de Estudos e Pesquisa em Aprendizagem Autorregulada - GEPAAR. Os dados foram reunidos por meio um questionário de informações demográficas no qual constavam informações sobre o curso em que os estudantes estavam matriculados, como também os motivos que os levaram a escolher as oficinas das quais participaram. Uma narrativa foi solicitada aos participantes ao final das oficinas. Cada estudante foi convidado a refletir sobre as dificuldades enfrentadas, bem como possíveis contribuições para 0 processo de aprendizagem. Apontaram também sugestões para a sequência do trabalho. Os dados foram analisados de forma qualitativa seguindo preceitos da análise de conteúdo. Constatou-se que os participantes revelaram que as oficinas oportunizaram um espaço importante de reflexão, trocas de experiências e aprimoramento das estratégias autorregulatórias, de maneira a contribuir para 0 desempenho acadêmico do estudante universitário.

Palavras-chave: Oficina pedagógica. Estratégias de aprendizagem. Estudante universitário. Ensino Superior.

\footnotetext{
${ }^{1}$ Doutora em Educação. Professora da Universidade Federal de Pelotas. Pesquisadora Pq2/CNPq. Apoio Universal edital CNPqn.28/2018.E-mail: frisonlourdes@gmail.com

2 Mestre em educação. Doutoranda pelo Programa de Pós-graduação em Educação da Universidade Federal de Pelotas
} 


\section{SELF-REGULATION CIRCUIT OF LEARNING: INTERLOCUTIONS WITH UNIVERSITY}

Abstract: This article aims to analyze the meanings and challenges faced by students who participated in the workshops about the self-regulation of learning (SLR), in the university context. This work is part of the research project "Ways of learning in the university environment: from self-regulation to life projects", which includes the LEARNING Circuit: self-regulation to learn, carried out by the Self-Regulatory Learning Studies and Research group - GEPAAR. Data were collected through a demographic information questionnaire containing information about the course in which students were enrolled, as well as the reasons that led them to choose the workshops in which they participated. A narrative was requested from participants at the end of the workshops. Each student was invited to reflect on the difficulties faced as well as possible contributions to the learning process. They also suggested ways to carry out subsequent work. The data were analyzed qualitatively following the precepts of the content analysis. It was found that the participants revealed that the workshops provided an important space for reflection, exchange of experiences and improvement of selfregulatory strategies, in a way that contributes to the academic performance of university students.

Keywords: Pedagogical workshop. Learning strategies. University student. Higher education.

\section{CIRCUITO DE AUTORREGULACIÓN DEL APRENDIZAJE: INTERLOCACIONES CON LOS UNIVERSITARIOS}

Resumen: Este artículo tiene por objetivo analizar los significados y los desafíos enfrentados por estudiantes universitarios a partir de talleres que invirtieron en prácticas asociadas a la autorregulación del aprendizaje en el contexto universitario. El trabajo forma parte del proyecto de investigación "Modos de aprender en el ambiente universitario: de la autorregulación a los proyectos de vida", que incluye el Circuito APRENDIZaje: autorregulación para aprender, realizado por el grupo de Estudios e Investigación en Aprendizaje Autorregulado - GEPAAR. Los datos se reunieron a través de un cuestionario de información demográfica en el que figuraban informaciones sobre el curso en que los estudiantes estaban matriculados, así como los motivos que los llevaron a elegir los talleres en los que participaron. Una narrativa fue solicitada a los participantes al final de los talleres. Cada estudiante fue invitado a reflexionar sobre las dificultades enfrentadas así como posibles contribuciones al proceso de aprendizaje. También apuntaron sugerencias para la secuencia del trabajo. Los datos fueron analizados de forma cualitativa siguiendo preceptos del análisis de contenido. Se constató que los participantes revelaron que los talleres proporcionaron un espacio importante de reflexión, intercambios de experiencias y perfeccionamiento de las estrategias autorregulatorias, de manera a contribuir al desempeño académico del estudiante universitario.

Palabras clave: Taller pedagógico. Estrategias de aprendizaje. Estudiante Universitario. Educación Superior. 


\section{Introdução}

Medo, angústias e incertezas. Talvez estes sejam os sentimentos mais comuns de diversos jovens que se encontram no ambiente universitário atualmente. 0 que poderia ser um ambiente propício para estimular a construção de conhecimentos e agregar valor à formação acadêmica e à própria formação pessoal, tem se esvaziado devido a exacerbada exigência acadêmica que envolve prazos, currículos fechados, multiplicidades de informações, pressões e responsabilidades para além da capacidade do ingressante (SÁEZ, et al., 2018).

A criação de espaços, que favoreçam uma melhor adaptação dos estudantes às exigências do contexto, são necessários para garantir sua permanência na universidade (GOMES; SOARES, 2013). As atividades propostas nas oficinas do Circuito APRENDIZagem: autorregulação para aprender, foram criadas justamente para ajudar os estudantes a superarem os obstáculos e as exigências que permeiam o mundo acadêmico. As oficinas foram desenvolvidas pelo Grupo de Estudos e Pesquisas em Aprendizagem Autorregulada - GEPAAR, vinculado a Universidade Federal de Pelotas/UFPel. Este grupo tem buscado atender as demandas acadêmicas dos estudantes, ao perceber as dificuldades que eles sistematicamente apresentam em suas aprendizagens. Para isso, investiram-se esforços ampliando e discutindo temas que refletem os modos de aprender dos estudantes, com o objetivo de analisar os significados e os desafios enfrentados por estudantes universitários a partir das oficinas do Circuito APRENDIZagem: autorregulação para aprender, as quais investiram em práticas associadas à autorregulação da aprendizagem no contexto universitário.

\section{Autorregulação da Aprendizagem}

A estrutura das oficinas do Circuito APRENDIZagem tem seu fundamento teórico nas pesquisas da Autorregulação, numa vertente social cognitiva (BANDURA, 1987; ZIMMERMAN, 2000, 2013). Nos últimos tempos, a autorregulação da aprendizagem vem sendo estudada por diversas abordagens teóricas que convergem para a concepção 
de que ela é um processo cíclico e dinâmico que engloba diversas dimensões. De acordo com Zimmerman (1989, 2000, 2013), a Autorregulação da Aprendizagem é "um processo proativo pelo qual os indivíduos constantemente organizam e gerenciam seus pensamentos, emoções, comportamentos e ambiente para atingir os objetivos acadêmicos" (RAMDASS; ZIMMERMAN, 2011, p. 198).

A autorregulação surge a partir das pesquisas de Albert Bandura (1987), sendo que o conceito self-regulation para a língua portuguesa se traduz por autorregulação, que muitas vezes é entendido, como se fosse apenas um protagonismo individual do sujeito, no entanto, pressupõe regulação partilhada que vem sendo pontuada por vários autores como Panadero, Järvelä, (2015) e Hadwin, Järvelä e Miller (2011) o que significa que para ser autorregulado, além do protagonismo individual que o sujeito assume, exige também envolvimento com o grupo de pares, pelo qual o sujeito interage para potencializar suas competências autorregulatórias. Neste sentido, trabalhar com oficinas autorregulatórias ajuda os estudantes a regularem de forma colaborativa as tarefas propostas no grupo, o que vai de forma individual e coletiva monitorando pensamentos, motivações, ações e emoções para alcançar os objetivos de aprendizagem. Portanto, sendo a autorregulação individual e socialmente compartilhada, ela assume um caráter complexo e multidimensional, pois exige dos estudantes consciência e controle dos processos de aprendizagem nos componentes cognitivo, comportamental, motivacional, afetivo e contextual, que auxiliam na identificação de suas metas e objetivos acadêmicos (ZIMMERMAN, 2009). Vygostky (1978) pontuava que as aprendizagens são pautadas na interrelação e na troca com os outros, sendo o conhecimento construído por meio de trocas e interações, utilizando correguladores entendidos como ações estimuladoras, guias, pistas e trocas com os pares, com o professor, o livro, para promoverem mudanças internas no estudante (JARVELÄ; HADWIN, 2013). Entende-se desta forma, que há no processo de autorregulação uma regulação individual e uma regulação externa provocada pela própria regulação e regulação do grupo, potencializando aos estudantes conhecimentos e tomada de decisão.

Entende-se que no processo da autorregulação da aprendizagem, os estudantes, na relação com o outro, direcionam esforços para aprender interagindo entre si, mas 
também atuando ciclicamente nas fases execução, antecipação e autorreflexão, pontuadas por Zimmerman (2002, 2013). Na primeira fase, os estudantes estabelecem os objetivos pedagógicos, selecionam estratégias de aprendizagem consideradas por eles ou pelo grupo como as mais adequadas; buscam também traçar um plano estratégico para alcançar os objetivos estabelecidos. Na fase de execução, os estudantes controlam as dimensões relacionadas à gestão da atenção, da motivação, do tempo, do ambiente físico e dos seus processos cognitivos para alcançarem os objetivos inicialmente traçados. 0 controle dessas dimensões representa grandes desafios aos estudantes, pois eles encontram muitas dificuldades para monitorar constantemente as estratégias escolhidas (ZIMMERMAN, 2013; VEIGA SIMÃO; FRISON, 2013). Na terceira fase, os estudantes precisam avaliar o processo e os resultados alcançados sobre os objetivos delineados na primeira fase. Neste processo autorreflexivo, os estudantes conseguem perceber a necessidade de traçar novos objetivos ou adotar novas estratégias.

Durante o processo cíclico é essencial uma atitude proativa frente à aprendizagem, para que o estudante consiga desenvolver competências acadêmicas como estabelecimento de metas; seleção e implementação de estratégias efetivas de aprendizagem; monitoramento o desempenho indicando sinais de mudança; aumento nas crenças positivas sobre as próprias capacidades; além de adaptação ao contexto social tornando-o compatível com os objetivos estabelecidos; gerenciamento do tempo, de forma eficiente; auto avaliação em relação às estratégias empregadas; atribuição causal sobre os resultados alcançados e, principalmente, adaptação dos métodos para estudos futuros (ZIMMERMAN, 2002, 2013). Essas capacidades quando bem desenvolvidas, conduzem o estudante a melhores resultados de aprendizagem e, consequentemente, acadêmicos, como revelam algumas pesquisas (GANDA, 2016; FREITAS-SALGADO, 2013).

\section{Circuito APRENDIZagem: autorregulação para aprender}

Desde 2014, o GEPPAR tem realizado pesquisas e intervenções pedagógicas procurando estimular o desenvolvimento de competências autorregulatórias nos 
estudantes. 0 circuito faz parte do projeto de pesquisa "Modos de Aprender no ambiente universitário: da autorregulação aos projetos de vida”, que já se encontra em sua terceira edição. Este grupo tem investido na pesquisa que busca compreender as trajetórias de insucesso de estudantes universitários e, para isso, em 2014 foi realizada uma pesquisa com 19 estudantes de Portugal (11 do sexo masculino) com idades entre 20 e 34 anos e 19 estudantes do Brasil (07 do sexo masculino) com idades entre 18 e 45 anos, de diferentes áreas científicas (Ciências Sociais e Humanidades, Ciências da Saúde e da Vida, Ciências Exatas e da Engenharia) de Universidades. Neste estudo, foi possível ampliar a visão das estratégias de aprendizagem utilizadas pelos estudantes. As ponderações pontuadas por estes estudantes mostraram a necessidade imprescindível de se criar propostas que promovam a aprendizagem, oportunizando maior autonomia e realização dos estudantes (FRISON; SIMÃO, no prelo).

Em 2016, frente aos resultados encontrados, entendeu-se que havia necessidade de se avançar implementando intervenções com múltiplas modalidades de atividades para atender as demandas dos estudantes. Desta forma, desenvolveram-se várias oficinas, ancoradas em temas sugeridos pelos estudantes. Essa experiência levou 0 grupo GEPAAR a tomar a decisão de desenvolver no projeto Circuito APRENDIZagem, com oficinas temáticas abordando as diversas dimensões da autorregulação da aprendizagem: cognitiva, comportamental, motivacional, afetiva e contextual. A partir de 2017, as oficinas do Circuito APRENDIZagem adquiriram o formato que as caracterizam até hoje.

O nome do circuito APRENDIZagem tem destaque na palavra aprendiz, pois enfatiza o sujeito da aprendizagem que, segundo a autorregulação da aprendizagem, remete ao protagonismo do sujeito como agente de sua aprendizagem, uma vez que precisa mobilizar-se para agir ativamente. No entanto, o agir ativamente requer também a colaboração do coletivo inserido no contexto. A palavra circuito deriva da ideia de que o aprendiz, ao passar pelas diferentes oficinas oferecidas no projeto, possa contemplar as diversas dimensões da sua aprendizagem. Sendo assim, o "Circuito APRENDIZagem: autorregulação para aprender" desenvolvido com base no modelo de Zimmerman (2013) tem uma proposta interventiva em formato de oficinas e ateliês, contendo atividades de curta duração, com o intuito de oportunizar aos estudantes a 
construção de saberes e experiências sobre as dificuldades enfrentadas no contexto universitário, planejando, executando e autoavaliando suas aprendizagens. Entende-se que as oficinas e os ateliês promoveram a regulação colaborativa, ou seja, enquanto o aprendiz partilhava com o grupo o que sabia, também aprendia (PANADERO; JARVELA, 2015). Neste sentido, buscou-se desenvolver e intensificar atividades para possibilitar aos discentes compartilhar experiências, aprender e aprimorar conhecimentos sobre as estratégias autorregulatórias, com a intenção de que consigam superar obstáculo e dificuldades que permeiam a vida acadêmica.

Todas as ações do Circuito APRENDIZagem foram pensadas, organizadas e dinamizadas por pesquisadores integrantes do GEPAAR. Este grupo é composto por doutorandos, pós-doutorandos, servidores, bolsistas de iniciação científica e professores parceiros de diversas áreas do conhecimento. As atividades foram oferecidas para toda a comunidade discente da UFPel por meio de editais publicados na página da Universidade e em outros meios de divulgação. 0 edital abrange duas modalidades de atuação: uma em que os estudantes se inscreveram nas oficinas que mais lhes interessavam e outra em que os professores inscreviam suas turmas para que a oficina fosse realizada durante suas aulas. Esta última modalidade permitiu uma maior abrangência do projeto, já que atendeu um público bem maior de estudantes. Além disso, considerou-se esta alternativa, uma possibilidade para superar a baixa frequência dos alunos nas oficinas que eles se inscreviam livremente. 0 fato é que se inscrevem, mas não compareceram por motivos diversos, como a falta de atenção em relação aos horários em que a oficina será sendo realizada. Entendeu-se que esta é uma das maiores dificuldades enfrentadas para a realização das intervenções acadêmicas. Em muitas pesquisas já publicadas (ROSÁRIO et al., 2005; MARTINS, 2016; GANDA, 2016; MIRANDA; NONTICURI; FRISON, 2017, 2018) nota-se que, mesmo os participantes se comprometendo a participarem das propostas interventivas, o número de estudantes que participaram de todos os encontros é baixo, pode-se dizer que somente 30\% comparecem (MIRANDA, et al., 2017, 2018).

Desde a primeira versão no projeto foram ofertadas 18 oficinas, sendo 14 delas na modalidade em que os estudantes fizeram suas escolhas e quatro na modalidade de os 
professores inscrevem suas turmas (MIRANDA; SCHIAVON; FRISON, 2018), conforme pode ser visualizado no quadro 1.

Quadro 1 - Oficinas ofertadas Circuito APRENDIZagem.

\begin{tabular}{|c|c|c|}
\hline 2016 & 2017 & 2018 \\
\hline \multicolumn{3}{|c|}{ Inscritas pelos estudantes } \\
\hline Procrastinação & $\begin{array}{l}\text { Ateliê (auto)formativo: os } \\
\text { sentidos de estar na } \\
\text { Universidade. }\end{array}$ & $\begin{array}{c}\text { Ateliê (auto)formativo: os sentidos } \\
\text { de estar na universidade. }\end{array}$ \\
\hline $\begin{array}{c}\text { Contexto e } \\
\text { aprendizagem }\end{array}$ & $\begin{array}{l}\text { Caixa de Pandora: vamos } \\
\text { falar das emoções }\end{array}$ & $\begin{array}{c}\text { Pandora: vamos falar das } \\
\text { emoções? }\end{array}$ \\
\hline $\begin{array}{l}\text { Autorregulação } \\
\text { em prol da } \\
\text { Leitura e Escrita }\end{array}$ & $\begin{array}{l}\text { Autorregulação em prol da } \\
\text { Leitura e Escrita. }\end{array}$ & $\begin{array}{c}\text { Desenvolvendo habilidades sociais } \\
\text { para a comunicação escrita }\end{array}$ \\
\hline $\begin{array}{l}\text { Estratégias de } \\
\text { aprendizagem }\end{array}$ & $\begin{array}{l}\text { Estratégias de } \\
\text { autorregulação da } \\
\text { aprendizagem }\end{array}$ & Como aprender na universidade? \\
\hline \multirow{3}{*}{$\begin{array}{l}\text { Realização de } \\
\text { trabalhos } \\
\text { acadêmicos }\end{array}$} & $\begin{array}{l}\text { Jogos reflexivos para } \\
\text { aprender. }\end{array}$ & $\begin{array}{l}\text { Geografia do acolhimento } \\
\text { universitário na cidade }\end{array}$ \\
\hline & \multirow{2}{*}{$\begin{array}{c}\text { Estratégias } \\
\text { autorregulatórias para a } \\
\text { resolução de problemas } \\
\text { matemáticos } \\
\text { contextualizados }\end{array}$} & $\begin{array}{c}\text { Estratégias autorregulatórias para } \\
\text { a resolução de problemas } \\
\text { matemáticos contextualizados }\end{array}$ \\
\hline & & $\begin{array}{c}\text { O estudante após o ingresso na } \\
\text { universidade: reflexões e } \\
\text { tensionamentos }\end{array}$ \\
\hline \multicolumn{3}{|c|}{ Inscritas pelos professores } \\
\hline \multirow{3}{*}{ Não foi ofertada } & \multirow{3}{*}{$\begin{array}{l}\text { Oficina de Estratégias de } \\
\text { Autorregulação da } \\
\text { Aprendizagem, } \\
\text { Procrastinação, Atenção e } \\
\text { Concentração }\end{array}$} & $\begin{array}{c}\text { Estratégias de autorregulação da } \\
\text { aprendizagem }\end{array}$ \\
\hline & & $\begin{array}{c}\text { O estudante após ingresso na } \\
\text { universidade: reflexões e } \\
\text { tensionamentos }\end{array}$ \\
\hline & & $\begin{array}{l}\text { Autorregulação em prol da leitura } \\
\text { e escrita }\end{array}$ \\
\hline
\end{tabular}

Fonte: Adatado de Miranda, Schiavon e Frison (2018).

Nota-se que as atividades do Circuito APRENDIZagem contemplaram diversas temáticas da autorregulação como estratégias autorregulatórias para a aprendizagem, entre elas: gestão da atenção, gestão do tempo e estratégias de estudo, além de competências específicas para a leitura e escrita acadêmica. Foram realizados Ateliês de (auto)formação que buscou trabalhar com os estudantes os sentidos de estar na universidade, instrumentalizando-os para o enfrentamento da resolução de problemas 
matemáticos; Tensionamentos e emoções gerados na vida universitária; Habilidades sociais; Geografia do acolhimento, entre outras (MIRANDA; SCHIAVON; FRISON, 2018). A maioria das oficinas foram realizadas em cinco sessões de quatro horas de duração, outras foram feitas com apenas um e dois encontros. Cada estudante teve livre arbítrio para se inscrever em mais de uma das oficinas do Circuito APRENDIZagem, conforme a disponibilidade de horário e preenchimento das vagas.

Ao perceber que o projeto tinha uma vasta repercussão na universidade, a cada ano a oferta de oficinas e ateliês foram ampliados, em média foram sete oficinas, variando conforme as parcerias obtidas no projeto, mas sempre buscando adequá-las às necessidades dos estudantes (Quadro 2). Em 2016, foram realizadas oficinas voltadas principalmente para o desenvolvimento de estratégias autorregulatórias para a aprendizagem, por exemplo: Procrastinação; Estratégias de autorregulação da aprendizagem; Realização de trabalhos acadêmicos e Autorregulação em prol da leitura e escrita. Esta última foi realizada em todas as edições do Circuito APRENDIZagem, assim como a oficina de Estratégias de autorregulação da aprendizagem. As oficinas como: Estratégias autorregulatórias para a resolução de problemas matemáticos contextualizados; Estratégias de autorregulação da aprendizagem; Autorregulação em prol da leitura e escrita; Caixa de Pandora: vamos falar das emoções; Ateliê (auto)formativo: os sentidos de estar na universidade e Estratégias de autorregulação da aprendizagem, foram ofertadas a partir da edição de 2017.

No quadro 2, visualiza-se ementa das oficinas que foram trabalhadas nas edições do circuito de 2017 e $2018^{3}$.

\footnotetext{
${ }^{3}$ Convenhamos apresentar apenas as ementas das oficinas de 2017 e 2018 por terem a mesma estrutura de organização, com oficinas similares e dados coletados, na modalidade de circuito.
} 
Quadro 2 - Oficinas ofertadas no Circuito APRENDIZagem em 2017 e 2018

\begin{tabular}{|c|c|}
\hline Oficinas ofertadas & Ementas \\
\hline $\begin{array}{l}\text { Estratégias de } \\
\text { autorregulação da } \\
\text { aprendizagem }\end{array}$ & $\begin{array}{l}\text { Conhecer o ciclo da autorregulação da aprendizagem e as } \\
\text { estratégias correspondentes a cada fase; conhecer as } \\
\text { características do estudante autorregulado, elaboração do plano } \\
\text { de estudos; o que é, como ocorre, como enfrentar o fenômeno da } \\
\text { procrastinação do estudo acadêmico; técnicas que estimulem a } \\
\text { atenção e concentração, bem como a gestão dos fatores internos e } \\
\text { externos que causam a distração. }\end{array}$ \\
\hline $\begin{array}{l}\text { Jogos reflexivos para } \\
\text { aprender. }\end{array}$ & $\begin{array}{l}\text { Propõe trabalhar com os jogos possibilitando a mediação } \\
\text { necessária e promovendo uma troca entre os estudantes, } \\
\text { perpassando pelas três fases da autorregulação (antecipação, } \\
\text { execução e autorreflexão). Busca-se promover o exercício da } \\
\text { reflexão na trajetória estudantil e na formação enquanto sujeito } \\
\text { dentro e fora da Universidade. }\end{array}$ \\
\hline $\begin{array}{l}\text { Ateliê (auto)formativo: os } \\
\text { sentidos de estar na } \\
\text { universidade }\end{array}$ & $\begin{array}{l}\text { Espaço de reflexão para (re)construir e ressignificar os sentidos do } \\
\text { Ensino Superior. Exercício reflexivo em relação a sua trajetória } \\
\text { enquanto estudante de graduação de uma Universidade Pública, } \\
\text { na produção de sentidos a sua caminhada e construção do seu } \\
\text { projeto de vida. }\end{array}$ \\
\hline $\begin{array}{l}\text { Pandora: vamos falar das } \\
\text { emoções? }\end{array}$ & $\begin{array}{l}\text { Desenvolver um diálogo sobre fatores de risco e de proteção que, } \\
\text { envolvem a depressão e a ansiedade no ambiente acadêmico, com } \\
\text { o objetivo de criar frestas de ar para pensarmos o bem viver. }\end{array}$ \\
\hline $\begin{array}{l}\text { Desenvolvendo } \\
\text { habilidades sociais para a } \\
\text { comunicação escrita }\end{array}$ & $\begin{array}{l}\text { Realização de atividades práticas em prol do desenvolvimento das } \\
\text { habilidades da Leitura e da Escrita do estudante. Embasa-se o } \\
\text { trabalho em diversas estratégias, ferramentas e teorias voltadas } \\
\text { para a autorregulação da leitura e da escrita. }\end{array}$ \\
\hline $\begin{array}{l}\text { Como aprender na } \\
\text { universidade? }\end{array}$ & $\begin{array}{l}\text { Oportunizar a estudantes universitários a ampliação e elaboração } \\
\text { de estratégias autorregulatórias para aprender os conteúdos } \\
\text { acadêmicos. }\end{array}$ \\
\hline $\begin{array}{l}\text { Geografia do acolhimento } \\
\text { universitário na cidade }\end{array}$ & $\begin{array}{l}\text { Promover aos alunos ingressantes o reconhecimento da UFPel, a } \\
\text { fim de que os mesmos estabeleçam, mais facilmente em seu } \\
\text { cotidiano práticas sócio-espaciais que propiciem o } \\
\text { reconhecimento, a apropriação e o pertencimento ao ambiente } \\
\text { universitário. }\end{array}$ \\
\hline $\begin{array}{l}\text { Estratégias } \\
\text { autorregulatórias para a } \\
\text { resolução de problemas } \\
\text { matemáticos } \\
\text { contextualizados }\end{array}$ & $\begin{array}{l}\text { Possibilidade de superação das dificuldades encontradas pelos } \\
\text { estudantes na disciplina de Cálculo, percebendo a aplicabilidade } \\
\text { da Matemática e com isso aumentando a motivação para a } \\
\text { conclusão do curso de graduação. }\end{array}$ \\
\hline $\begin{array}{l}\text { O estudante após o } \\
\text { ingresso na universidade: } \\
\text { reflexões e } \\
\text { tensionamentos }\end{array}$ & $\begin{array}{l}\text { Proporcionar a reflexão a respeito das dificuldades com que se } \\
\text { deparam no ambiente acadêmico. Dessa forma, esta oficina visa } \\
\text { promover um diálogo sobre as possibilidades de enfrentamento às } \\
\text { dificuldades que se colocam na caminhada acadêmica, com a } \\
\text { intenção de incentivar que os universitários a se tornem agentes } \\
\text { dos seus percursos formativos. }\end{array}$ \\
\hline
\end{tabular}

Fonte: Adaptado de Miranda, Schiavon e Frison (2018). 


\section{Metodologia}

O Circuito APRENDIZagem tem dois eixos de atuação, o primeiro com ênfase no ensino e o segundo na pesquisa. Desta forma, ao realizá-los coletaram-se dados que os pesquisadores do grupo GEPAAR analisaram para compreender como os estudantes se revelavam e como compreendiam o espaço da oficina para pensar a própria aprendizagem. Vieira, Valquind (2002, p. 11) destacam que "toda oficina necessita promover a investigação, a ação e a reflexão". Desse modo, as oficinas serviram como espaço de produção de dados que são analisados e confrontados com a teoria para legitimar a condição de projeto de pesquisa.

0 trabalho realizado na coleta de dados sobre as oficinas e ateliês teve ênfase numa abordagem qualitativa e foram considerados os tópicos: escolhas, motivos, presenças e o envolvimento dos estudantes nas oficinas do Circuito APRENDIZagem realizadas em 2017 e 2018. A sistemática do grupo GEPAAR foi organizar as oficinas no primeiro semestre e realizá-las no segundo semestre de cada ano letivo, com encontros sistemáticos, variando de 2 a 5 sessões. No entanto, algumas oficinas, por serem mais solicitadas pelos estudantes, foram realizadas durante os dois semestres, por exemplo a que abordou "Estratégias de autorregulação da aprendizagem”.

Os estudantes, ao acessarem o banner publicado na página da UFPel, eram dirigidos ao edital que apresentava todas as informações como: o horário de cada oficina, número de sessões, vagas, propostas, ementas, referencial teórico, metodologia de trabalho e orientações e explicações para que os estudantes pudessem conhecer um pouco mais sobre a dinâmica das oficinas ofertadas. No término das inscrições publicou-se na página da UFPel a lista dos estudantes contemplados nas vagas existentes. Nesta ocasião foi enviado a cada estudante um e-mail para confirmar sua vaga. Ainda assim, quando o número de inscritos superava as vagas ofertadas, chamavam-se mais 10 estudantes para compor a lista de suplentes. Os editais foram mantidos na página da UFPel por um período de duas semanas em média, estendendose algumas vezes para mais alguns dias, conforme a aderência dos estudantes. Por vezes, devido à baixa divulgação, as oficinas tiveram poucos inscritos, sendo impulsionadas a partir da prorrogação, uma vez que se envia e-mail para todos os estudantes cadastrados em oficinas anteriores. 


\section{Participantes}

Para este estudo, o lócus foi de 222 estudantes que se inscreveram nas duas edições do Circuito APRENDIZagem, sendo 107 em 2017 e 115 em 2018. Desse total, também se considera para a análise dos dados 122 estudantes que participaram mais de $75 \%$ das oficinas, correspondendo a 55 em 2017 e 67 estudantes em 2018.

\section{Instrumentos de coleta dos dados}

Os dados foram coletados por meio de um questionário de informações demográficas no qual continham perguntas sobre o curso que os estudantes estavam matriculados, indagando também, sobre os motivos que os levaram a escolher as oficinas e nas quais participaram. No final das oficinas também foram recolhidos dados a partir de uma narrativa em que os alunos deveriam abordar se as dificuldades foram superadas, motivos que os levaram a participar das oficinas e as contribuições da oficina para as dificuldades pontuadas e sugestões para futuras oficinas.

\section{Procedimentos da coleta dos dados}

No ato das inscrições, os interessados preenchiam a ficha com dados pessoais, nela destacavam os motivos de suas escolhas. Ao longo das oficinas, outros instrumentos foram utilizados de acordo com a dinâmica de cada oficina, porém, para este artigo utilizou-se o questionário de informações demográficas e a narrativa, nas quais relataram as contribuições que as oficinas oportunizaram. Por meio delas, podese verificar se as expectativas iniciais foram atendidas e quais as sugestões para propostas futuras.

A recolha dos dados seguiu as normas éticas recomendadas para uma pesquisa científica. Foi solicitado o consentimento livre e esclarecido dos participantes, garantindo sigilo em relação aos dados coletados. Para este artigo os estudantes foram identificados pela letra $E$ (estudantes) acrescida do número 1 a 222 que corresponde ao número dos instrumentos coletados, destacando que do E1 ao E105, corresponde aos 
participantes que se inscreveram em 2017 e do E106 ao E222 referente aos participantes de 2018. Para os dados gerados a partir das narrativas, a identificação seguiu a mesma lógica, foram identificados com a letra $\mathrm{N}$ de 1 a 55 para as narrativas de 2017 e de N56 a N122 para as narrativas de 2018. Ao longo do texto foram incluídos alguns dos depoimentos verbalizados ou escritos por estudantes no percurso das oficinas.

\section{Análise dos dados}

Os dados recolhidos foram submetidos à análise de conteúdo (BARDIN, 2011) dela emergindo categorias de análise, as quais visam compreender o processo autorregulatório dos estudantes percebido ao longo das oficinas.

\section{Resultados}

Antes porém de apresentar a análise dos significados e dos desafios enfrentados por estudantes universitários a partir das oficinas, as quais investiram em práticas associadas à autorregulação da aprendizagem no contexto universitário, é preciso apresentar a abrangência da implementação das oficinas na universidade e, na sequência pontuar as duas categoria emergidas: a) Expectativas iniciais dos estudantes ao participarem das oficinas; b) Contribuições e alternativas para a superação de obstáculos e desafios enfrentados por estudantes universitários.

\section{Abrangência do projeto}

Desde o início do projeto "Modos de aprender na universidade", iniciado em 2016, as oficinas ofertadas com a possibilidade de os estudantes escolherem as que gostariam de participar, conquistou o público acadêmico da UFPel. 0 número de inscritos nas primeiras oficinas não foi muito expressivo, no entanto, houve aumento significativo nas versões posteriores (Tabela 1). No primeiro edital, em 2016, foram ofertadas quase 100 vagas, para 5 oficinas disponibilizadas. Dessa oferta, apenas 47 
estudantes se inscreveram e a participação efetiva foi de $75 \%$, correspondendo, respectivamente a 35 estudantes. Os dados mostraram que os inscritos participaram ativamente das atividades propostas, mesmo não tendo todas as vagas preenchidas. Após as oficinas, ao analisar-se os dados coletados, percebeu-se que elas atenderam as expectativas dos estudantes, ratificando a importância do trabalho realizado, mostrando que o mesmo deveria ser mantido e, na medida do possível, ampliado (MIRANDA; SCHIAVON; FRISON, 2018).

Na edição do Circuito APRENDIZagem de 2017, além da ampliação do projeto com novas oficinas e parcerias, houve um aumento no número de inscritos. Das 120 vagas ofertadas, 107 foram preenchidas, com participação de 55 estudantes. Na oferta do Circuito de 2018, disponibilizaram-se 140 vagas, que contou com a inscrição de 115 estudantes. A participação com 67 estudantes foi maior do que na edição anterior.

Após a realização das inscrições, cada ministrante da oficina entrava em contato com os estudantes, via e-mail e whatsapp para saudá-los e confirmar sua vaga. Intencionava-se com esta ação estimular e confirmar o comparecimento dos estudantes nos encontros agendados. No entanto, no primeiro encontro, verificou-se ausência de muitos inscritos. Na edição de 2017, dos 107 inscritos, compareceram 55 estudantes e na de 2018, 67 que permaneceram até o final das oficinas. Nas duas edições do Circuito (2017 e 2018) houve mais de 220, mas a presença foi de 122 estudantes, ou seja, uma desistência de mais de $50 \%$, o que efetivamente levou o grupo GEPAAR a avaliar as razões pelas quais os estudantes não compareciam nas oficinas, uma vez que eles mesmos haviam feito a escolha de nelas participarem. No quadro abaixo, pode-se ver a relação dos inscritos e participantes de acordo com a área de conhecimento (Quadro 3).

Como foi dito, o número de inscritos não reflete a realidade efetiva de participação dos estudantes nas oficinas. Percebeu-se que o número daqueles que realmente frequentam as oficinas após as inscrições é bem menor que as inscrições realizadas. Ao longo dos três anos do projeto das oficinas, percebeu-se que um dos problemas está relacionado a falta de investimento em divulgação do projeto, mas também da falta de organização dos estudantes. Entende-se que o número de inscritos foi satisfatório, se comparado ao número de vagas ofertadas, porém, há uma 
disparidade entre 0 número de inscritos e o número dos que efetivamente compareceram às oficinas.

Quadro 3 - Aderência dos estudantes nas oficinas do Circuito APRENDIZagem.

\begin{tabular}{|c|c|c|c|c|c|c|c|}
\hline \multirow{2}{*}{$\begin{array}{c}\text { Sujeitos/ } \\
\text { Áreas de conhecimento }\end{array}$} & \multicolumn{3}{|c|}{ Inscritos } & \multicolumn{3}{|c|}{ Participantes } & \multirow{2}{*}{$\begin{array}{l}\text { Número de } \\
\text { cursos } \\
\text { abrangidos } \\
\text { nas } \\
\text { inscrições }\end{array}$} \\
\hline & $\begin{array}{c}201 \\
7\end{array}$ & $\begin{array}{c}201 \\
8\end{array}$ & $\begin{array}{c}\text { Tota } \\
\text { l }\end{array}$ & $\begin{array}{c}201 \\
7\end{array}$ & $\begin{array}{c}201 \\
8\end{array}$ & $\begin{array}{c}\text { Tota } \\
\text { l }\end{array}$ & \\
\hline Ciências exatas e da terra & 12 & 13 & 25 & 5 & 11 & 16 & 10 \\
\hline Ciências biológicas & 1 & 2 & 2 & 1 & 1 & 2 & 2 \\
\hline Engenharias & 12 & 4 & 16 & 4 & 2 & 6 & 8 \\
\hline Ciências da saúde & 11 & 17 & 28 & 7 & 7 & 14 & 6 \\
\hline Ciências agrárias & 2 & 6 & 8 & 0 & 3 & 3 & 4 \\
\hline $\begin{array}{l}\text { Ciências sociais e } \\
\text { aplicadas }\end{array}$ & 15 & 18 & 33 & 7 & 11 & 18 & 13 \\
\hline Ciências humanas & 28 & 33 & 61 & 13 & 19 & 32 & 8 \\
\hline Linguística, letras e artes & 25 & 23 & 48 & 17 & 13 & 30 & 7 \\
\hline Multidisciplinar & 1 & 0 & 1 & 1 & 0 & 1 & 1 \\
\hline Total & 107 & 115 & 222 & 55 & 67 & 122 & 59 \\
\hline
\end{tabular}

Fonte: As autoras (2019)

Ao tabular os dados do não comparecimento nas oficinas, constatou-se que os estudantes afirmam a incompatibilidade de horários com as aulas que estão matriculados, além de outros compromissos assumidos. Muitos estudantes não deram retorno sobre o não comparecimento nos encontros das oficinas que se inscreveram. Este fenômeno, do não comparecimento, parece ser comum em diversas outras propostas pedagógicas, quando os estudantes não só desta universidade, como de outras instituições não assumem responsabilidades (MARTINS, 2016; ROSÁRIO et al., 2005).

Diversos estudos mostram que apesar das intervenções iniciarem com um número razoável de participantes, que se comprometem a participarem de todo o processo, não frequentam a todas as sessões propostas, totalizando até $50 \%$ de ausências. Rosário et 
al., (2005), destacam que dos 29 estudantes inscritos, participaram apenas 15, isso representa $51 \%$ de presença em todas as seis sessões por eles realizadas. Martins (2016) também corrobora pontuando que em seu estudo, dos 40 participantes, apenas 27 participaram de 83 a $100 \%$ das seis sessões, o que equivale dizer que 13 ou $32 \%$ desistiram. Supõe-se que os estudantes não apareceram devido à falta de interesse, falta de tempo, muitos compromissos do semestre ou que as propostas não atendam às expectativas dos mesmos. Esta hipótese poderia ser verdadeira caso não houvesse um grande número de inscritos ou que aqueles que se inscreveram desistissem após os primeiros encontros das oficinas. Porém, o que acontece é que nas fichas de inscrições constata-se o interesse por parte dos estudantes em participar das propostas, justificando o interesse nas oficinas pelo assunto a ser abordado, afirmando serem elas uma possibilidade para melhorar o aprendizado, para adquirir novas experiências e gerenciar as dificuldades enfrentadas no contexto da universidade (SCHIAVON; MIRANDA; FRISON, 2018). Os estudantes que realmente participam dos primeiros encontros, permanecem até o final e relatam que o trabalho contribuiu de maneira significativa para o processo de aprendizagem. Obviamente tem-se uma incongruência entre dois aspectos. Por um lado, os estudantes se mostram interessados em participar das propostas, por outro, poucos comparecem. E os que aparecem, avaliam muito bem os temas e atividades trabalhadas nas oficinas.

Infere-se que o fenômeno da desistência em massa das oficinas é algo muito similar ao que acontece em relação às disciplinas que estão matriculados. Assumem múltiplas tarefas e depois percebem que não conseguem dar conta de todas elas e acabam procrastinando. Sobre os estudantes que se inscreveram e participaram das oficinas, verificamos que estão matriculados em 48 cursos diferentes, desde a graduação à pós-graduação. Os inscritos provinham de 59 cursos, sendo que não compareceram até o final estudantes de 11 cursos. Os estudantes eram de diferentes áreas de conhecimento, como Ciências Sociais e Aplicadas, Ciências Agrárias, Ciências Humanas, da Linguística, Letras e Artes, das Ciências Exatas e da Terra, Ciências Biológicas, Engenharias e Ciências da Saúde e multidisciplinar (CNPQ, 2018). Teve também a participação de quatro estudantes da pós-graduação dos cursos de especialização, mestrado e doutorado. 
Os cursos das áreas Ciências Humanas, Linguística, Letras, Artes e Ciências Sociais e Aplicadas foram os que mais aderiram à proposta do Circuito APRENDIZagem, tanto no número de inscritos como no número de estudantes presente nas oficinas. 0 curso de Letras teve maior participação dos estudantes, com 33 inscritos e 21 participantes, seguidos dos cursos da Pedagogia com 17 inscritos e 9 participantes e Geografia com 14 inscritos e 9 participantes. Os demais cursos com seis a oito inscritos foram dos cursos de, Ciências Sociais, História, Matemática, Filosofia, Antropologia, Educação Física, Enfermagem e Nutrição.

As oficinas que tiveram maior número de inscritos em 2017 foi a oficina "Caixa de Pandora: Vamos falar das emoções?”, “Estratégias de autorregulação da aprendizagem”, “Jogos reflexivos para aprender” e "Autorregulação em prol da Leitura e Escrita”. Em 2018, a preferência foi “O estudante após o ingresso na universidade: reflexões e tensionamentos”, "Desenvolvendo habilidades sociais para a comunicação escrita", "Caixa de Pandora: vamos falar das emoções" e "Vamos aprender na universidade". Em suma, os cursos que mais se inscreveram nas oficinas tanto nas oferecidas em 2017 como em 2018, são os cursos das Letras e da Pedagogia. Desses cursos, a preferência foi pela oficina "Autorregulação em prol da Leitura e Escrita", "Caixa de pandora: vamos falar das emoções" e "Desenvolvimento de habilidades sociais para a comunicação".

Para melhor compreender os resultados encontrados, apresentam-se, a seguir, as duas categorias: a) Expectativas iniciais dos estudantes ao participarem das oficinas; b) Contribuições e alternativas para a superação de obstáculos e desafios enfrentados por estudantes universitários.

\section{Expectativas iniciais dos estudantes ao participarem das oficinas}

No que concerne às expectativas iniciais dos estudantes, a partir da análise dos dados foram percebidas seis subcategorias: identificação com o tema, avanços na aprendizagem, troca de experiências, capacitação profissional, questões emocionais e gerenciamento e compatibilidade de horários. 
Quadro 4 - Subcategorias emergidas da análise de conteúdo das fichas de inscrição.

\begin{tabular}{|c|c|c|c|c|}
\hline \multirow{2}{*}{ Subcategorais } & \multicolumn{3}{|c|}{ Frequência } & \multirow{2}{*}{$\begin{array}{c}\text { Porcentage } \\
\mathbf{m}\end{array}$} \\
\hline & 2017 & 2018 & Total & \\
\hline Identificação com o tema & 35 & 54 & 89 & $40 \%$ \\
\hline Avanços na aprendizagem & 24 & 22 & 46 & $21 \%$ \\
\hline Capacitação profissional & 13 & 18 & 32 & $14 \%$ \\
\hline Questões emocionais & 8 & 24 & 32 & $14 \%$ \\
\hline Troca de experiências & 9 & 10 & 19 & $9 \%$ \\
\hline $\begin{array}{l}\text { Desenvolvimento de habilidades } \\
\text { de comunicação e de escrita }\end{array}$ & - & 15 & 15 & $6 \%$ \\
\hline Autoconhecimento & - & 12 & 12 & $5 \%$ \\
\hline $\begin{array}{l}\text { Gerenciamento e } \\
\text { compatibilidade de horários }\end{array}$ & 1 & 9 & 10 & $4, \%$ \\
\hline Identificação com o tema & 35 & 54 & 89 & $40 \%$ \\
\hline Avanços na aprendizagem & 24 & 22 & 46 & $21 \%$ \\
\hline
\end{tabular}

Fonte: As autoras (2019).

Dentre as subcategorias que despertou maior interesse por parte dos estudantes foram: identificação com os temas abordados nas oficinas; questões emocionais e a vanços a aprendizagem.

Cabe pontuar que para os estudantes, a escolha da oficina está ligada ao assunto ou a proposta: "Me interesso pelo tema da oficina" (E36); "Achei a proposta muito interessante"; (E2) ou ainda, por ter relação com vivências acadêmicas "Eu escolhi essas oficinas pois me chamaram bastante a atenção e também porque são temas que eu tenho pensado muito sobre eles ultimamente, principalmente agora na faculdade" (E131). Os dados anteriores foram apontados por $40 \%$ dos participantes, sendo estes os motivos em destaque sobre a escolha das oficinas. Alerta-se que antes de escolherem a oficina pretendida, os estudantes podiam, a partir da ementa, identificar os assuntos que seriam abordados em cada oficina. Como tinha várias oficinas que coincidiam nos horários, isso foi determinante para que eles fizessem sua escolha em relação a oficina que melhor se aproximava de suas necessidades. Zimmerman (2013) enfatiza que é fundamental os estudantes serem proativos perante suas escolhas. 
A subcategoria relativa às Questões emocionais foi pontuadas por $14 \%$ dos estudantes, uma vez que ela está diretamente ligada ao assunto que os preocupa suas emoções, principalmente quando atreladas ao ambiente universitário. Relatam a necessidade de auxílio para aprender, para lidar com as próprias emoções como a depressão e ansiedade, muitas vezes, gerada pelo afastamento da família, por estarem estudando em outra cidade. Alguns depoimentos mostram “após a entrada na faculdade houve a piora da minha depressão e ansiedade" (E120), "escolhi porque com a mudança de cidade veio junto muitas mudanças psicológicas” (E161). Também revelaram ser as oficinas um espaço onde podem procurar ajuda e expressar suas angústias.

Pode-se perceber no depoimento de um estudante seu entusiasmo ao encontrar um espaço no qual pode discutir e refletir sobre assuntos tão pertinentes como a depressão e ansiedade "achei muito interessante e uma surpresa agradável saber que a Universidade de Pelotas está com uma programação dessas, inclusive e, principalmente, abrindo espaços para falarmos dos nossos sentimentos e emoções, que é algo muito sério hoje em dia. Eu mesmo como sou de fora do estado, passei muitas coisas emocionais, além do assunto da depressão e ansiedade que afeta a muitos de nossa época caótica e complexa" (E134). No processo da aprendizagem, a dimensão da emoção não pode ser negligenciada. Assim como as dimensões cognitivas, metacognitivas e contextuais são de suma importância para a autorregulação da aprendizagem (BZUNECK; RUFINI, 2010).

A subcategoria que teve ênfase na Melhora do aprendizado foi uma das mais pontuadas pelos estudantes (21\%). Nela se investiu sobre a busca por um melhor desempenho na universidade e aprendizado de novas estratégias de estudo: "Às vezes me deparo com certas dificuldades em relação a certos conteúdos, então acredito que a oficina, pode me ajudar a tirar algumas dúvidas e me dê dicas em como melhorar meu desempenho acadêmico" (N117).

Outro ponto a ser destacado refere-se ao interesse quanto à ampliação da aprendizagem de novas estratégias, com as quais se possa melhorar o rendimento acadêmico. As incertezas de não saber como estudar ou de se sentir perdido diante dos desafios e obstáculos enfrentados nos estudos, ou ainda, nas dificuldade de saber por onde começar ou que estratégias utilizar, levou alguns estudantes a buscar a 
alternativa da oficina, desejando melhorar os conhecimentos e ampliar seu desempenho acadêmico: "Escolhi estas oficinas para aprimorar meu desempenho e minha formação" (E79); “Gosto de ter experiências novas na minha formação” (E51); “acredito que essa oficina será muito válida, inclusive contribuirá para melhorar meu desempenho acadêmico" (E124). Zimmerman e Risemberg (1997) propõem seis questões fundamentais para ajudar no processo de aprender. Essas questões estão associadas a diferentes dimensões psicológicas e podem ser consideradas graus de liberdade para a tomada de decisão. As dimensões pontuadas pelos autores são: porqué - relacionado a motivação para fazer algo; como - a utilização de um método de estudo; quando - ligado a gestão do tempo; o qué - relativo ao desempenho; onde - o lugar escolhido para estudar, e com quem - grupo com quem estuda, com quem estabelecem trocas e parcerias. Esses componentes da autorregulação da aprendizagem ajudam a potencializar no estudante a tomada de decisões pessoais, com a finalidade de regular o seu processo de aprendizagem (VEIGA SIMÃO, FRISON, 2013).

Os estudantes relataram dificuldades referentes à própria aprendizagem, à adaptação no que tange ao contexto universitário e a escolha do curso. Revelaram: "Considero interessante participar dessas oficinas, uma vez que tenho apresentado dificuldades em organizar meus estudos de modo produtivo" (E18). Dificuldades de integração na academia também foi constatada: “A necessidade de me sentir integrado à vida acadêmica e melhor orientar minha caminhada, visto estar ingressando tardiamente em uma universidade e sentir-me um tanto deslocado" (E12). Por fim, dúvidas e confusões: "Escolhi a oficina sobre os sentidos de estar na universidade na expectativa de entender melhor a minha situação acadêmica, na esperança de clarear minhas dúvidas quanto a necessidade de um curso de graduação e as possíveis consequências disso, ou a falta dele" (E34). Ou conforme E2: "A oficina contribuiu com o que eu já vinha pensando, ajudou bastante, pois também apontou onde estou falhando. Mostrou-me saídas para coisas que pareciam não ter solução como a procrastinação e as estratégias autoprejudiciais. Deixou mais claro como superar obstáculos existentes na vida da maioria dos universitários".

Os medos, angústias e incertezas iniciais quanto ao processo de aprendizagem e adaptação na universidade deram indícios de estarem sendo sanados, mesmo que 
parcialmente ao longo das propostas das oficinas. As expectativas também foram reveladas pelas contribuições provocadas ao participar das oficinas. A forte motivação apontada por eles para estarem nas oficinas deu-se pelo fato de se identificarem com os conteúdos a serem abordados, além da possibilidade de conhecer novas estratégias e poder compartilhar com o grupo de amigos percebendo que os problemas de uns são praticamente os problemas de todos.

As angústias de não conseguir se expressar corretamente diante das formalidades encontradas na universidade, de não saber fazer uma solicitação aos departamentos, ou de conseguir expressar suas ideias numa prova e artigos, levaram os estudantes a procurarem as oficinas relacionadas à escrita. A subcategoria desenvolvimento de habilidades de comunicação e escrita teve grande aderência entre os inscritos, mesmo sendo elas ofertadas em 2018. De acordo com o depoimento da estudante E124: "é fundamental o indivíduo saber se comunicar de forma adequada por escrito, principalmente nos dias de hoje, pois vivemos na era tecnológica, na qual o principal meio de comunicação é a escrita, via mensagens".

A subcategoria Capacitação profissional, 14\% dos estudantes expressaram a preocupação relacionada a saber aproveitar as oportunidades da universidade para melhorar sua formação acadêmica e para, no futuro, atuar profissionalmente. A estudante E150 escreveu "para um maior conhecimento, saber como direcionar minha carreira depois da graduação e ter mais referências no currículo”.

A subcategoria Troca de experiências também foi revelada nas narrativas, pois os estudantes afirmaram que as oficinas constituíram um espaço para a troca e aprendizado, identificando dificuldades semelhantes entre os estudantes. Afirmaram que, além de agregar novas experiências possibilitou novas aprendizagens: "Gosto de ter experiências novas na minha formação" (E51); “Noto que nos cursos da UFPel a evasão é altíssima, talvez com as oficinas poderemos diminuir este triste cenário, a partir de reflexões com os estudantes” (E183); “Já de imediato transpareceu meu interesse e necessidade de participar da oficina 5, pois sinto necessidade de ter auxílio psicológico dentro da universidade, por exemplo: rodas de conversas ou palestras que falem sobre a ansiedade e a depressão que tanto me assombra. Gostaria de participar e 
saber se não estou sozinha. É na universidade que tenho a verdadeira sensação de tristeza e pavor" (E217).

A pesquisa evidenciou que para melhorar o aprendizado, ter novas experiências, buscar solução para as dificuldades e superar obstáculos enfrentadas pelos estudantes durante o curso, é preciso partilhar com os outros suas angústias, assim ao se sentirem apoiados pelos amigos e pares, conseguem melhor autorregular seus compromissos, tarefas assumidas e aprendizagens. Alguns desses pontos também foram analisados por Schiavon, Miranda e Frison (2018), referentes às oficinas de 2017.

\section{Contribuições e alternativas para a superação de obstáculos e desafios enfrentaados por estudantes universitários}

As contribuições das oficinas foram evidenciadas em três subcategorias essenciais, a partir das narrativas coletadas após as intervenções, as quais segundo os estudantes, contribuíram muito para a formação de um espaço de reflexão e troca de experiências, além de minimizar as dificuldades iniciais apresentadas quando se inscreveram para participar das oficinas.

Quanto à primeira subcategoria, Espaço de reflexão, os estudantes relataram que as oficinas fazem pensar sobre o que fazem, porque fazem ou deixam de fazer tais coisas. Isso revelou que podem ter um comportamento mais positivo frente à aprendizagem e suscitou o desejo de implementar mudanças sobre modo como vinham estudando e enfrentando as dificuldades. Com estas reflexões, puderam avaliar a própria formação e perceberam que muitas das ações que realizavam, se modificadas, poderão ajudar no avanço do sucesso acadêmico.

De acordo com a narrativa do estudante N35 "acredito que a oficina nos faz pensar, refletir sobre as atividades propostas, na maioria das vezes repetimos ações e pensamentos que nos foram apresentados, sem ao menos pensar sobre o mesmo, esquecemos das várias possibilidades e meios que podemos criar e modificar para resolvê-los" (N23). Outro estudante destaca que deve "parar, pensar e ver como eu devo me organizar para estudar e vencer as dificuldades, não posso me sentir incapaz, devo 
procurar algum jeito ou maneira para aprender. Com certeza vai me ajudar agora nas minhas próximas atividades acadêmicas depois dos dias de hoje".

Ao autoavaliar as próprias ações, os estudantes se apoiam nos colegas, identificando dificuldades parecidas, as quais podem ser enfrentadas de modos diversos, indo ao encontro de expectativas iniciais, pontuadas quando se inscreveram para participar das oficinas. Percebeu-se que Minimizar as dificuldades iniciais, esteve presente na maioria dos depoimentos dos estudantes. 0 estudante N18 aborda este fato "saio daqui, hoje, mais leve! Por saber que as dificuldades que enfrento não são impossíveis de solucionar. As dicas serão muito importantes daqui para a frente, tanto na organização pessoal quanto na organização daquilo que não podemos controlar, como as aulas (tarefas fixas)". A estudante enfatizou que a "autoavaliação é muito importante, ela me faz mudar - ou tentar mudar - o que é necessário para melhorar o rendimento" (N18).

Ao perceberem suas dificuldades os estudantes se dão conta que não estão sozinhos, porque a troca de experiências entre os pares possibilita o entendimento de muitas questões.

As questões emocionais também foram referidas nos relatos. Para exemplificar, um excerto da narrativa do estudante N83, que pontuou a angústia que enfrenta na universidade.

O tema das emoções foi um ponto que mais me envolveu na semana de prevenção ao suicídio (setembro amarelo), como buscar um equilíbrio em meio a tantas tensões/pressões (internas e externas). No meio universitário são questões preciosíssimas que merecem ser levantadas e não escondidas. Precisamos falar de saúde/bem-estar mental/emocional na universidade, precisamos discutir os sentidos do Ensino Superior, o que significa fazer uma [...]”. (N83, grifo nosso).

Este relato evidencia a angústia que este estudante enfrenta na universidade, ele reflete um pouco do que está pontuado nas demais narrativas de outros participantes. 


\section{Conclusão}

A partir dos resultados encontrados neste estudo, infere-se a necessidade dos estudantes desenvolverem competências para autorregular suas aprendizagens no ambiente universitário. As oficinas permitiram investir no ensino e no aprimoramento das competências para que os estudantes pudessem, ao utilizar estratégias autorregulatórias, obter melhores resultados no desempenho acadêmico, fortalecendo sua autonomia, motivação, autoestima e autoeficácia para aprender. Obviamente, não temos ainda, devido ao pouco tempo da realização das oficinas resultados comprovados nas avaliações dos estudantes, no entanto, temos fortes depoimentos que mostram os avanços pessoais em relação às dificuldades reveladas pelos estudantes.

Além disso, constatou-se que o ambiente universitário é composto por muitas possibilidades, mas também por muitos desafios, sendo que o estudante se sente pouco preparado para enfrentá-los. Tem-se a crença de que o estudo realizado pode ajudar na reflexão dos estudantes sobre os obstáculos que eles encontram no convívio e cotidiano universitário, se apropriando de alternativas e estratégias para superá-los. Mesmo assim, a superação dos obstáculos precisa ser pensada tanto pelos estudantes, os quais devem ser mais responsáveis pelas suas aprendizagens, quanto pela equipe de professores e gestores das universidades, os quais devem oferecer condições pedagógicas e de acolhimento propícias para que os estudantes aprendam. Todo estudante pode se autorregular, mas, para isso, é preciso que as estratégias sejam ensinadas.

Para finalizar, conclui-se que é emergente a continuidade de projetos e proposta que contribuam com as aprendizagens dos estudantes, para que consigam avançar em suas escolhas acadêmicas. Mas também é preciso que se invista na continuidade de pesquisas que possam mostrar resultados consistentes para contribuir com a literatura da área e com as práticas pedagógicas desenvolvidas no contexto universitário.

O grupo GEPAAR continua com este projeto, atendendo maior número possível de estudantes universitários, intencionando que reflitam sobre seus comportamentos, sobre o que fazem para aprender, sobre métodos que os auxiliem a potencializar a aprendizagem autorregulada, para que possam traçar planos de um futuro melhor. 


\section{Referências}

BANDURA, A. A teoria social cognitiva na perspectiva da agência. In: BANDURA, A.; AZZI, R. G.; POLYDORO, S. (org.). Teoria social cognitiva: conceitos básicos. Porto Alegre: Artmed, 2008. p. 69-96.

BARDIN, L. Análise de conteúdo. 3. ed. São Paulo: Edições 70, 2011.

BZUNECK, J. A.; RUFINI, S. É. Aprendizagem escolar em contextos competitivos. In: BORUCHOVITCH, E.; BZUNECK, J. A. (org.). Aprendizagem: processos psicológicos e o contexto social na escola. 2. ed. Petrópolis: Vozes, 2010.

CNPQ. Tabela de áreas do conhecimento. 2018. Disponível em: http://www.cnpq.br/documents/10157/186158/TabeladeAreasdoConhecimento.pdf. Acesso em: 12 nov. 2018.

FREITAS-SALGADO, F. A. Autorregulação da aprendizagem: intervenção com alunos ingressantes. 2013. Tese (Doutorado em Educação) - Universidade Estadual de Campinas, Campinas, 2013.

GANDA, D. R. A autorregulação da aprendizagem de alunos em curso de formação de professores. um programa de intervenção. 2016. Tese (Doutorado em Educação) - Faculdade de Educação, Universidade Estadual de Campinas, Campinas, 2016.

GOMES, G.; SOARES, A. B. Inteligência, habilidades sociais e expectativas acadêmicas no desempenho de estudantes universitários. Psicologia: reflexão e crítica, Porto Alegre, v. 26, n. 4, p. 780-789, 2013. Disponível em: http://www.scielo.br/pdf/prc/v26n4/19.pdf. Acesso em: 20 set. 2017.

HADWIN, A. F.; JÄRVELÄ, S.; MILLER, M. Self-regulated, co-regulated, and socially shared regulation of learning. In: ZIMMERMAN, B. J.; SCHUNK, D. H. Handbook of self-regulation of learning and performance. Londres: Routledge, 2011. v. 30, p. 65-84.

JARVELA; S.; HADWIN, A. New frontiers: regulating learning in CSCL. Educational Psychologist, Hillsdale, v. 48, n. 1, p. 25-39, 2013.

MARTINS, R. M. M. Estratégias de aprendizagem em universitários: avaliação e intervenção. Tese (Doutorado em Psicologia) - Faculdade de Psicologia, Universidade São Francisco, Itatiba, 2016. Disponível em:

https://www.usf.edu.br/galeria/getImage/427/17279032934113009.pdf. Acesso em: 20 abr. 2016.

MIRANDA, C. A. G. R.; NONTICURI, A. R.; FRISON, L. M. B. Estratégias autorregulatórias para o controle do desempenho em estudantes universitários: mudanças após processo reflexivo. Revista de Estudios e Investigacion en Psicología Y Educación, Elviña, n. 1, 2017. DOI: 10.17979/reipe.2017.0.01.2726.

MIRANDA, C. A. G. R.; SCHIAVON, A. A.; FRISON, L. M. B. Circuito de autorregulação para aprender - APRENDIZagem: uma proposta para o envolvimento estudantil. In: CIDU CONGRESSO IBERO-AMERICANA DE DOCÊNCIA UNIVERSITÁRIA, 10., 2018, Porto Alegre. Anais [...]. Porto Alegre: PUCRS, 2018. p. 1-10.

PANADERO, E.; JARVELA“; S. Socially shared regulation of learning: a review. European Psychologist, London, v. 20, n. 3, p. 190-203, 2015. DOI: 10.1027/1016-9040/a000226. 
RAMDASS, D.; ZIMMERMAN, B. J. Developing self-regulation skills: the important role of homework. Journal of Advanced Academics, Thousand Oaks, v. 22, n. 2, p. 194-218, 2011.

ROSÁRIO, P.; MOURÃO, R.; SOARES, S.; ARAÚJO, J. F.; NUÑEZ PEREZ, J. C.; GONZÁLEZPIENDA, P.; GRÁCIO, M. L.; CHALETA, E.; SIMÕES, F.; GUIMARÃES, C. Promover as competências de estudo na universidade: projeto cartas do Gervásio ao seu umbigo. Psicologia da Educação, Covilha, v. 4, n. 2, p. 57-69, 2005.

SÁEZ, F. M.; DÍAZ, A. E.; PANADERO, E.; BRUNA, D. V. Revisión sistemática sobre competencias de autorregulación del aprendizaje en estudiantes universitarios y programas intracurriculares para su promoción. Formación Universitaria, La Serena, v. 11, n. 6, dez. 2018. DOI: $10.4067 /$ S0718-50062018000600083.

SCHIAVON, A. A.; MIRANDA, C. A. G. R.; FRISON, L. M. B. Motivação dos acadêmicos para o envolvimento em oficinas autorregulatórias. I $n$ : CIDU - CONGRESSO IBERO-AMERICANA DE DOCÊNCIA UNIVERSITÁRIA, 10., 2018, Porto Alegre. Anais [...]. Porto Alegre: PUCRS, 2018. p. 1-10.

VEIGA SIMÃO, A. M.; FRISON, L. M. B. Autorregulação da aprendizagem: abordagens teóricas e desafios para as práticas em contextos educativos. Cadernos de Educação, Pelotas, v. 45, p. 2-20, 2013.

VIEIRA, E.; VALQUIND, L. Oficinas de ensino: o quê? por quê? como?. 4. ed. Porto Alegre: EDIPUCRS, 2002.

VYGOTSKY, L. S. Mind in society: the development of higher psychological processes. Cambridge, MA: Harvard University Press, 1978.

ZIMMERMAN, B. J. A social cognitive view of self-regulated academic learning. Journal of Educational Psychology, Arlington, v. 81, n. 3, p. 329-339, 1989.

ZIMMERMAN, B. J. Achieving self-regulation: the trial and triumph of adolescence. In: PAJARES, F.; URDAN, T. (ed.). Academic motivation of adolescents. Greenwich, CT: Information Age Publishing, 2002. p. 1-27.

ZIMMERMAN, B. J. Attaining self-regulation: a social cognitive perspective. I $m$ : BOEKAERTS, M.; PINTRICH, P.; ZEIDNER, M. (ed.). Handbook of self-regulation. San Diego: Academic Press, 2000. p. 13-39.

ZIMMERMAN, B. J. From cognitive modeling to self-regulation: a social cognitive career path. Educational Psychologist, Hillsdale, v. 48, n. 3, p. 135-147, 2013.

ZIMMERMAN, B. J. Self-regulation: where metacognition Intersect. In: HACKER, D. J.; DUNLOSKY, J.; GRAESSER, A. C. Handbook of metacognition in education. Ney York: Routledge, 2009. p. 299-316.

ZIMMERMAN, B. J.; RISEMBERG, R. Self-regulatory dimensions of academic learning and motivation. In: PHYE, G. D. (ed.). Handbook of academic learning. Cambridge: Academic Press, 1997. p. 105-125. 